$\underline{\text { Short Report }}$

\title{
Improving the breastfeeding practices in the Estate Sector of Sri Lanka: A matter that needs urgent intervention
}

\author{
*Jagath C Ranasinghe ${ }^{1}$, Asanka C Manawaduge², Suneth B Agampodi ${ }^{3}$ \\ Sri Lanka Journal of Child Health, 2021; 50(4): 709-710 \\ DOI: https://doi.org/10.4038/sljch.v50i4.9892 \\ (Key words: Estate sector, Exclusive breastfeeding, Expressed breast milk, Sri Lanka)
}

Sri Lanka achieved the green status in breastfeeding $(\mathrm{BF})$, the first ever country to achieve this status in the world, in $2020^{1}$. Demographic Health Survey 2016 reported that $82 \%$ infants aged $0-5$ months are exclusively breastfed and $92 \%$ infants continued $\mathrm{BF}$ at one year ${ }^{2}$. Though debatable whether these numbers reflect true exclusive breastfeeding (EBF) rates, these indicators are considered as best in the world $^{3,4}$. Despite these high rates, discrepancies exist in BF rates among urban, rural and estate sectors $^{2}$. In the estate sector, suboptimal practices of EBF are common, especially due to early return of mothers to work, lack of knowledge and management skills of expressed BF and other reasons $^{5}$. In general, the estate management provides three months of paid maternity leave, a special allowance after child birth, crèche facilities and the childcare homes system to encourage women workers returning from maternity leave.

Kotmale Medical Officer of Health $(\mathrm{MOH})$ area serves a population of 67,741 , including 1065 children less than 2 years old. There are about 14 estates in this area and many Public Health Midwife (PHM) areas comprise $100 \%$ from the estate population. There is one $\mathrm{MOH}, 3$ Public Health Instructors (PHIs), 25 PHMs serving 25 PHM areas and about 50 crèche carers serving 40 crèche facilities. Some PHMs and all crèche carers are trained by the Plantation Human Development Trust and others are from the government services.

${ }^{1}$ National Hospital of Kandy, Sri Lanka, ${ }^{2}$ Medical Officer of Health Office, Kothmale, Sri Lanka ${ }^{3}$ Department of Community Medicine, Faculty of Medicine and Allied Sciences, Rajarata University of Sri Lanka, Sri Lanka

*Correspondence: c.ranasinghe0323@gmail.com

https://orcid.org/0000-0002-1586-2987

(Received on 28 August 2021: Accepted after revision on 17 September 2021)

The authors declare that there are no conflicts of interest

Personal funding was used for the project.

Open Access Article published under the Creative

Commons Attribution CC-BY (c) (i) License
While providing routine care in the Kotmale $\mathrm{MOH}$ area, we observed that suboptimal feeding practices are very high in this community. Though the crèche facilities are encouraging BF, the lack of technical skills and equipment to train mothers on expressing breast milk have led to the routine practice of bottle/ formula feeding in these centres and at home. Expressed breast milk has never been used in these facilities. The babies cared for in crèche facilities received formula (majority), tea, coriander, cow's milk or other preparations as per desire and availability. The usual perception is that it is "difficult to change the behaviour".

With collaboration of the estate management and MOH Kotmale, we conducted lectures using audiovisuals, practical sessions using dummies, roleplays and street dramas to empower PHMs, crèche carers and the mothers on expressing breast milk, storing breast milk and feeding babies with expressed breast milk. A limited number of breast pumps were also provided through community participation. Strengthening of practices was done on all 25 PHMs of the area. We evaluated the situation after six months.

The records kept by the carers and the MOH staff show that within this period 36 infants aged less than 6 months (who should have been exclusively on breast milk) were taken care of by crèche facilities. Average time of stay at crèche was six and a half hours. Of these babies, only 9 (25\%) were exclusively breast fed. Of the remainder, 11 (40.7\%) infants received expressed breast milk, showing that this behaviour could be introduced to this population with proper training. Nevertheless, 21 infants received formula feeds with or without breast milk while they were in the day-care facility. During home stay, $33(91.7 \%)$ were exclusively breast fed, one $(2.8 \%)$ was breast fed by another mother and only $2(5.6 \%)$ were receiving top up formula milk. A major limitation was the absence of proper data to compare the feeding practices before the intervention either in crèche or at home.

Though there was a dramatic improvement in the use of expressed breast milk in the crèche after this initiative, a significant portion of babies were still on 
formula feeding. A closely monitored long-term follow-up with repeated training and surveillance is required until this practice is internalized by the estate community as their own behaviour.

\section{Acknowledgements}

We thank the Community Medicine clerkship appointment group of medical students, the Faculty of Medicine and Allied Sciences, Rajarata University of Sri Lanka, Mr Ranga Gunasekara, Ferland Estate Superintendent, $\mathrm{MOH}$ office staff and Crèche carers.

\section{References}

1. World Breastfeeding Trends Initiative Press Briefing: The World Breastfeeding Trends Initiative (WBTi) congratulates Sri Lanka on achieving first "Green" nation status supporting breastfeeding women. 2020. Available from:

https://www.worldbreastfeedingtrends.org /uploads/resources/document/wbti-pressrelease-9-jan-2020.pdf

2. Department of Statistics. Demographic and Health Survey Sri Lanka. 2016.

3. Agampodi SB, Agampodi TC. de Silva A. Exclusive breastfeeding in Sri Lanka: Problems of interpretation of reported rates. International Breastfeeding Journal 2009; 4: 14.

https://doi.org/10.1186/1746-4358-4-14

PMid: 19941654 PMCid: PMC2789039
4. Ratnayake HE, Rowel D. Prevalence of exclusive breastfeeding and barriers for its continuation up to six months in Kandy district, Sri Lanka. International Breastfeeding Journal 2018; 13: 36. https://doi.org/10.1186/s13006-018-0180y

PMid: 30116290 PMCid: PMC6085653

5. Senarath U, Dibley MJ, Godakandage SS, Jayawickrama H, Wickramasinghe A, Agho KE; South Asia Infant Feeding Research Network. Determinants of infant and young child feeding practices in Sri Lanka: secondary data analysis of Demographic and Health Survey 2000. Food and Nutrition Bulletin 2010; 31(2): 352-65. https://doi.org/10.1177/156482651003100 223

PMid: 20707238 